Singh, J., Deng, M., and Cheng, J.C.P. (2018). "Implementation of mass customization for MEP layout design to reduce manufacturing cost in one-off projects." In: Proc. $26^{\text {th }}$ Annual Conference of the International. Group for Lean Construction (IGLC), González, V.A. (ed.), Chennai, India, pp. 625-635. DOI: doi.org/10.24928/2018/0519. Available at: www.iglc.net.

\title{
IMPLEMENTATION OF MASS CUSTOMIZATION FOR MEP LAYOUT DESIGN TO REDUCE MANUFACTURING COST IN ONE-OFF PROJECTS
}

\author{
Jyoti Singh ${ }^{1}$, Min Deng ${ }^{2}$, and Jack C.P. Cheng ${ }^{3 *}$
}

\begin{abstract}
MEP systems are complex system representing a considerable portion of commercial and industrial projects, comprising $25 \%-40 \%$ of the total project cost and covering more than $50 \%$ of the total duration of the project. The layout design of MEP system is generally based on client and system requirements, space limitations, interference within the system as well as with other trades. Not much consideration is given to the design optimization as per fabrication and constructability perspective thereby often adding significant cost and time to a project in term of its component manufacturing.

This paper introduces Design for Manufacture approach into MEP system design to reduce the manufacturing cost of varieties of MEP components by using mass customized components. Mass customization is the ability to design and produce customized products to meet customer needs at reduced cost and duration.

We propose a framework to automatically develop the layout of the piping system using mass customized components as a reference, which can be used for other MEP aspects such as Mechanical \& Electrical with relevant changes. We hypothesize that using mass customized MEP components will increase the efficiency and reduce the cost of manufacturing the MEP components. The paper presents a theoretical framework that is the basis for further research.
\end{abstract}

\section{KEYWORDS}

Mass customization, standardization, cost.

1 Research Postgraduate Student, Dept. of Civil and Environment Engineering, The Hong Kong University of Science and Technology, Hong Kong, China, +852 5106 4954, jsinghab@ connect.ust.hk

2 Research Postgraduate Student, Dept. of Civil and Environment Engineering, The Hong Kong University of Science and Technology, Hong Kong, China, +861 18815275040, mdengaa@connect.ust.hk

3 Associate Professor (Corresponding Author), Dept. of Civil and Environment Engineering, The Hong Kong University, of Science and Technology, Hong Kong, China, +852 2358 8186, cejcheng@ust.hk 


\section{INTRODUCTION}

Mechanical, Electrical and Plumbing (MEP) systems are complex system representing a considerable portion of commercial and industrial projects, comprising $25 \%-40 \%$ of the total project cost and covering more than $50 \%$ of the total duration of the project (Riley et al. 2005). In fact, the cost associated with the MEP engineering and design can be up to $50 \%$ of the total investment in some large-sized public projects.

Specialized consultants and contractors are responsible for MEP systems design including responsibility for checking clearance, identifying routes and fabrication details and installation locations (Korman et al. 2001).

MEP systems directly influence the total cost of the project as well as its operating efficiency, safety, energy utilization, and flexibility of the architectural and structural design. Considering the value of the MEP portion of a facility, this research investigates how to efficiently layout the MEP systems to reduce manufacturing cost of the MEP components.

The layout design of MEP system is generally based on client and system requirements, space limitations, interference within the system as well as with other trades. Not much importance is given to the design optimization as per fabrication and constructability perspective thereby often adding significant cost and time to a project in term of its component manufacturing. This paper introduces Design for Manufacture (DFM) approach into MEP system design to reduce manufacturing cost of varieties of MEP components by using mass customized components.

Mass customization is the ability to design and produce customized products to meet customer needs at lesser cost and duration. Manufacturing and production have been a big contributor to improved quality and sustainability of human life. Current market trends, such as customer demand for variety, high product quality, short product life cycles, and low cost, have ensured the need for efficient, robust, responsive, and sustainable manufacturing. (Kwok et al. 2016).

Innovative practitioners begin to throw away the old paradigm of mass production and find their way to a new paradigm, mass customization, by creating variety and customization through flexibility and responsibility to meet customers' diverse and ever changing needs at near mass production prices (Pine 1993; Tseng and Jiao 1996; Jensen et al. 2013). The basic idea of this theory is to reuse standard modules and parts across different product variants in order to enable mass customization (Meyer and Lehnerd 1997; HööK and Stehn 2008; Gerth 2013)

However, customized product is very challenging to be produced in masses using traditional manners, and the business has to wait for today's advanced technologies to enable profitable customization (Bourell et al. 2009).

One of the reasons behind the low level of intelligent MEP system design is that MEP consultant does not fully utilize new techniques emerged like mass customization along with the development of information technology, such as the Building Information Modeling/Model (BIM) technology. 
There is a need to automate the process of MEP design layout with the use of mass customized components to reduce the manufacturing cost of the components. Using Building information modelling as a tool to assist DFM appears to be an effective approach to overcome various challenges.

\section{LITERATURE REVIEW}

Designing MEP systems involves defining the location and routing for different components of building systems to comply with diverse design and operation criteria. (Barton 1993). Preferably, the best coordinated design location is considered as most economical and effective arrangement that meets critical design criteria and performance specifications (Korman et al. 2003)

\subsection{PROBLEMS WITH CURRENT MEP DESIGN}

MEP system is composed of the numerous components with different size and shapes having complex logic structure among them. Whether MEP systems are installed onsite or in a factory as part of modular construction project, the coordination of the different components and their fabrication has historically been a challenge (Lu 2008).

Table 1: Problem with current MEP design

\begin{tabular}{lll}
\hline \multicolumn{1}{c}{ Current practice } & Reference \\
\hline - $\begin{array}{l}\text { Effective MEP coordination requires recalling and } \\
\text { integrating knowledge regarding design, construction, } \\
\text { operations, and maintenance of each MEP system. }\end{array}$ & \\
- $\begin{array}{l}\text { This multi-discipline process is time consuming and } \\
\text { expensive. }\end{array}$ & Korman et al. 2003 \\
Most visible parts of MEP design only focus on \\
geometry and functionality of the building systems. \\
- $\begin{array}{l}\text { Current focus of MEP system design is only to satisfy } \\
\text { performance requirements for the specific project and }\end{array}$
\end{tabular}

\subsection{RESEARCH RELATED TO MEP SYSTEM DESIGN}

Before conducting our research to reduce manufacturing cost of different MEP components, we investigated various researches related to MEP system design criteria and intent and its components fabrication and construability issues. We found that most researches focus on coordination issue of MEP systems in design as well as construction phase, as described in following researches table 2: 
Table 2: Research related to MEP system design

\begin{tabular}{|c|c|c|}
\hline Author & & Research work \\
\hline Korman et al. 2003 & & $\begin{array}{l}\text { Developed a knowledge framework for MEP coordination that } \\
\text { reflected the complexity and variety of all the components }\end{array}$ \\
\hline Korman et al. 2006 & & $\begin{array}{l}\text { Developed a computer-based tool to assist in MEP systems } \\
\text { coordination to assist in planning the construction of MEP systems }\end{array}$ \\
\hline $\begin{array}{l}\text { Korman and } \\
(2011)\end{array}$ & & $\begin{array}{l}\text { Explored how BIM can be utilized to increase the opportunities for } \\
\text { prefabrication of MEP systems for modular construction projects }\end{array}$ \\
\hline Wang et al. 2016 & & $\begin{array}{l}\text { A practical BIM framework was developed for coordinating MEP } \\
\text { layout from the preliminary design to construction stage }\end{array}$ \\
\hline
\end{tabular}

Although a significant amount of research efforts has been carried out in improving the MEP system design for better performance, operation and its construction. No attention was given to a vast variety of components in MEP system and their manufacturing cost. The fabrication of these components constitutes huge cost and time. Thus, there is need to focus on how the manufacturing cost of various MEP components can be curtailed while not comprising with system performance and operation.

The theory of mass customization aims to offer increased product flexibility by standardizing components without increasing manufacturing costs, thus appears to be an effective approach to overcome manufacturing cost of a vast variety of MEP system components. Studies advocate the application of mass customization (MC) in building as it can provide value-added products at reasonable cost. There is still lack of studies of the use of mass customization in MEP system.

\subsection{SUMMARY}

The primary objectives of various researches are to design MEP systems layout such that it follows universal design, occupancy requirements, environmental regulations, fire safety, space constraints, maintenances and daily operations requirements,

No regard is given to massive diversity of components in MEP system and their manufacturing cost. The fabrication of each and every component constitutes huge cost and time, thereby often adding significant cost and duration to a project in terms of its components fabrication. Thus, there is increased need to focus on how the manufacturing cost of various MEP components can be curtailed keeping its performance and operation at its best.

This research focuses on design optimization by opting Design for Manufacture approach into MEP system design to reduce manufacturing cost of varieties of MEP components by using mass customized components. Therefore, we propose a framework to automatically develop the layout of the piping system using mass customized 
components as a reference which can be used for other MEP aspects such as Mechanical $\&$ Electrical with relevant changes.

\section{DETERMINATION OF PIPING COST}

In order to develop a piping layout which is economical and also satisfy all the operation and design criteria's. The first step is to know what are the drivers for piping cost.

The piping process can be divided into four phases: designing, pipe fabrication, transportation to site, and site installation. Piping cost estimation depends on many variable factors such as:

- Direct Costs related to piping: The direct cost of piping is related to the procurement and installation of piping along with other piping accessories. This cost generally deals with raw materials, labor, energy, space, etc.

- Indirect Costs related to piping: This cost deals with design and engineering cost, which basically comprise of cost of design and engineering of the piping system, construction supervision, contractor's fees (Technology Fee), etc.

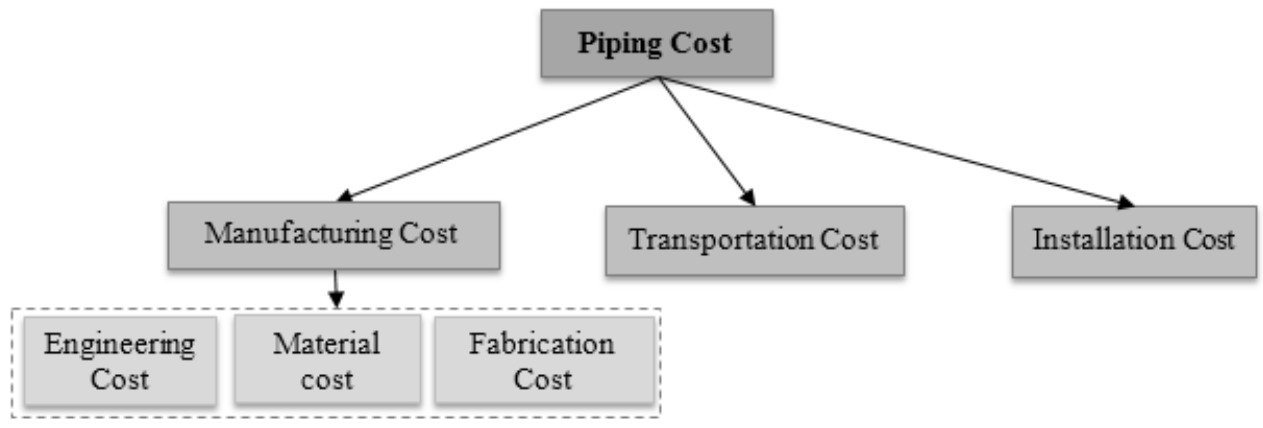

above mentioned various factors can be summarised into three wider categories: Manufacturing cost, Transportation cost and Installation cost, as shown in figure 1.

Figure 1: Overview of piping cost

There exist various solutions which can aid to decrease the above mentioned costs. Some of the are listed below:

- Engineering cost: opting for various technological advancement and automation.

- Material cost: choosing proper layout i.e. opting shorter route for costly pipes.

- Fabrication cost: using DFM, use of mass customized components.

- Transportation cost: supply chain management practices.

- Installation costs: use of simulation, opting for simple connection, modularization, Design for assembly (DFA). 


\section{FRAMEWORK ON PIPING SYSTEM LAYOUT DESIGN USING MASS CUSTOMIZED COMPONENTS}

A piping works engineer should have wide engineering knowledge, understanding of engineering economics, methods of pipe fabrication, costs of metallurgical, erection and installation requirements and knowledge of other disciplines such as mechanical, civil, electrical and instrumentation engineering to discuss coordination requirements.

In order to design piping system so that its component can be mass customized, there is need to find appropriate sizing option as per the design criteria's and proper layout (without any clashes)

\section{SIZING OF A PIPE SYSTEM}

Pipe sizing and routing is one of the most important and critical activities for any piping project. The selection of the optimal pipe route (length), diameter, wall thickness, material and equipment location are typically the result of economic scrutiny and investment evaluation of the most reasonable structure developed through the design phase.

Pipe size is determined with proper dimension calculations considering various parameters and design calculations. Pipe sizing decisions affect project economics substantially which include cost of pipe and accessory as well as cost of support etc. Pipe route should preferably be shortest with minimum bends, closer to wall or other devices to support them, with no obstruction around etc

The term sizing of a piping system refers to the completion of two independent design functions: the fluid flow design and the pressure-integrity design.

Before the start of the above mentioned designing process there is need to fix the position of source and demand points (its position is prefixed as per some guidelines and experience). Next a preliminary pipe route clash free route having appropriate length, least bends etc. to know the approximate route length of the pipe. After the preliminary layout of the piping system is achieved, the design process will proceed.

\section{System Flow Design}

- The objective is to determine the minimum acceptable inside diameter of each segment of the piping system that will accommodate the design flow rate.

- The detailed system flow design of a piping system depends on various inputs such as shown in table 3 : 
Table 3: Input type for system flow design

\begin{tabular}{|c|c|}
\hline Input Type & Parameters \\
\hline Space (geometry) & $\begin{array}{l}\text { Size and configuration (length of the pipe, Location of } \\
\text { source, demand points) }\end{array}$ \\
\hline Fluid characteristics & Design temperature, viscosity, density \\
\hline System requirements & $\begin{array}{l}\text { Required pressure, flow rate, type of connections and bends } \\
\text { etc. }\end{array}$ \\
\hline Material attributes of pipes & pipe wall frictional drag \\
\hline
\end{tabular}

\section{Pressure Wall Pressure (Integrity) Design}

- After the fluid design is complete and the minimum inside diameters of the various segments of the piping system are determined, the piping wall pressure design may proceed. It determines the minimum or nominal pipe wall thickness and the pressure rating of the in-line components, such as fittings and valves.

- The Pressure wall pressure (Integrity) design of a piping system depends on various inputs such as shown in table 4:

Table 4: Input type for Pressure wall pressure (Integrity) design

\begin{tabular}{ll}
\hline \multicolumn{1}{c}{ Input Type } & \multicolumn{1}{c}{ Parameters } \\
\hline Design pressure & $\begin{array}{l}\text { Maximum pressure at expected conditions. Generally, } \\
\text { the maximum flange pressure at design pressure is } \\
\text { used. }\end{array}$ \\
$\begin{array}{l}\text { Diameter of pipe as calculated by } \\
\text { system flow design }\end{array}$ & \\
$\begin{array}{l}\text { System requirements } \\
\text { Material attributes of pipes }\end{array}$ & $\begin{array}{l}\text { Type of joints, design temperature } \\
\text { thermal insulation }\end{array}$ \\
\hline
\end{tabular}

With the two above mentioned design process the necessary minimum dimensional requirement of various piping components is determined. For example, for pipe, its minimum required diameter, thickness for the adopted route lengths are known. The final piping layout on the basis the above design process is still to be achieved.

\section{LAYOUT AND SIZE OPTIMIZATION}

After calculation of minimum size requirement of the components, adoption of appropriate size of the components is done. Normally, a size just bigger (next integer value) than the minimum one is chosen and is assigned to the particular section of layout.

Treading to the path of this research, there is a need to determine what can be the best layout and optimum dimension for a particular piping component which can be used repetitively in order to mass customize whole piping layout on the basis of the above two designs. The selection of proper size of the components is influenced by various economical aspects for example, if the size is too large than what is required can be 
highly uneconomical, etc. Therefore, a fast and reliable optimization technique is required to be introduced to get the best fitted standard dimensions of a component to mass customize the piping layout.

An optimization operation will be carried out to choose best layout and standardize each pipe segments and layout in terms of length, diameter and thickness, height. The potential optimization technique which can solve the objective of the proposed research are Genetic Algorithm or Simulated Annealing, as they work on search technique and provide the best alternatives to the objective function based on the fitness of the parameters among the given possible populations. Weights should be assigned to different parameters of the objective function. The objective function should also comprise of penalty function (having infinite weights) if the constraints are violated as well as bonus function (negative weight components) if the standard pipe sizes are used, this can be understand by a simple equation (3) below:

Minimize: $\mathrm{f}_{\text {single }}=\mathrm{w}_{1} \mathrm{f}_{\text {length }}+\mathrm{w}_{2} \mathrm{f}_{\text {bends }}+\cdots \cdots+\mathrm{w}_{\mathrm{n}-1} \mathrm{f}_{\text {penalty }}+\mathrm{w}_{\mathrm{n}} \mathrm{f}_{\text {bonus }}$

Where, $f_{\text {singleP }}=$ pipe route; $f_{\text {length }}=$ length of the route; $f_{\text {bends }}=$ No of bends; $f_{\text {penalty }}=$ penalty function (eg. Technical constraints); $f_{\text {bonus }}=$ bonus function (eg. use of standardized components) and $\mathrm{w}_{1}, \mathrm{w}_{2}, \mathrm{w}_{\mathrm{n}-1}, \mathrm{w}_{\mathrm{n}}$ are respective weights assigned for the different parameters mentioned.

Using the above two independent design processes and optimization technique, a pipe system design layout is obtained with standardize pipe segments and accessories. A design checks and loading and service condition check is done to confirm the obtained layout. To show the proposed pipe design process, a theoretical framework is developed to obtain pipe system layout having standardized components as shown in figure 2.

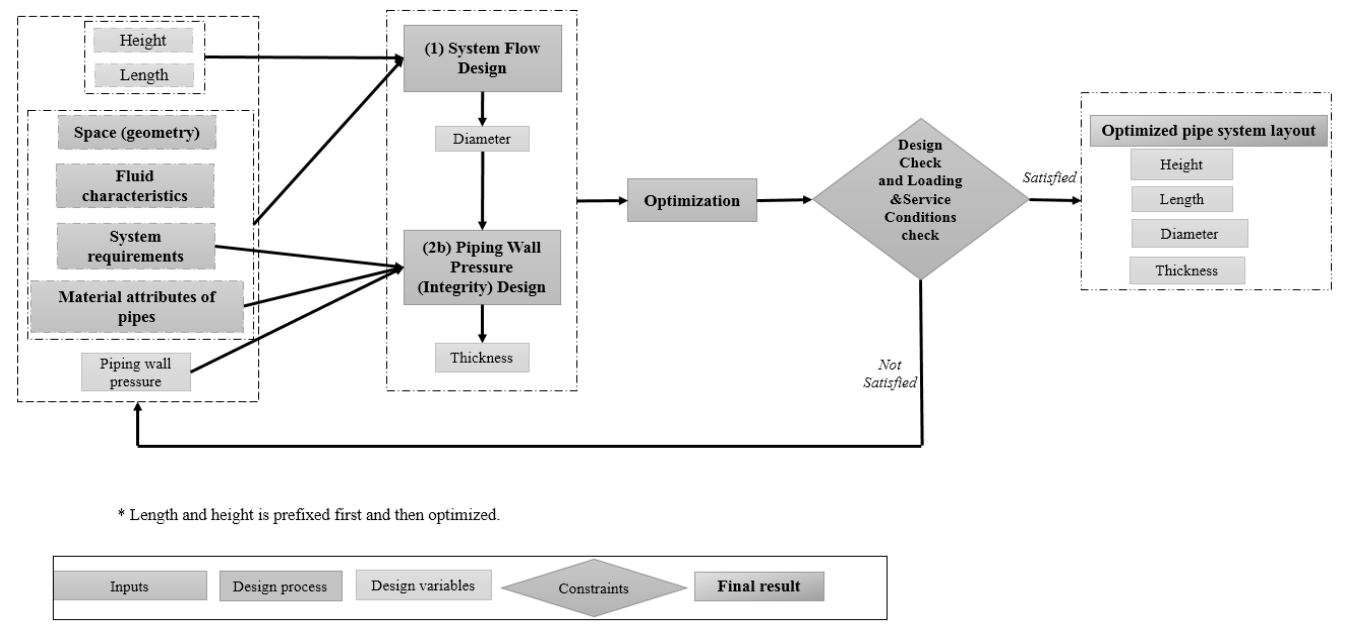

Figure 2: Framework to standardize piping components

\section{CONCLUSION AND DISCUSSION}

The traditional approaches for MEP design layout requires the calculation of minimum sizing requirements and thereby choosing of appropriate size as per the availability 
convenience. Several research efforts were made to MEP design layout and the most visible parts of MEP system design focus only on the geometry and functionality requirement of the building systems. However, none of them considered the importance of manufacturing cost associated with variety of MEP components and ease of the fabrication of these components, during design stage. The fabrication of diverse components in MEP system constitutes huge cost and time, thereby often adding significant cost and duration to a project in terms of its components fabrication. Thus, there is requisite on how the manufacturing cost of various MEP components can be curtailed keeping its performance and operation at its best.

Mass customization combines the individualization and flexibility to custom-made a products and matching its level to that of mass production, thereby offering a lower unit cost. The benefits mass customization can provide concerning to the different types of variety of components in a particular product is comprehended in this research and represented by optimization technique to provide advice for MEP design for manufacturing.

This paper presents a theoretical framework that focus on design optimization by opting Design for Manufacture approach into MEP system design to reduce manufacturing cost of varieties of MEP components by using mass customized components. The developed framework also focus on manufacturing aspects of MEP component in addition to operation al requirement which will solve many of the current MEP design problem such as not accounting constructability issue, low level of standardization etc. As this research aims to use BIM as a means to develop the framework, the whole MEP design process can be speeded up thereby potentially reducing the designing time of MEP systems.

This approach has potential for various EPC projects (oil and gas plants, power plants, metallurgy plants etc.) as they engage huge amount of investment and also consist of massive diverse components and sub components and thus reducing the manufacturing cost of various components and sub components can contribute significantly to the whole project cost.

As the developed piping framework is theoretical in nature. More development and mathematical validation are required to prove the proposal. Therefore, extending the framework for the validations will be considered in the future work. The developed framework can be extended for other trades such as Mechanical etc. Further research on quantitative aspect of cost and time will be beneficial to influence customer value.

\section{REFERENCES}

Barton, P.K. (1983). "Building Services Integration.” E \& FN Spon, London.

Bourell, D. L., Leu, M. C., and Rosen, D. W. (2009). "Roadmap for Additive Manufacturing: Identifying the Future of Freeform Processing." Technical Report, The University of Texas at Austin, Austin, TX. 
Gerth, R. (2013). "The Role of Production Topology in Information Based Structuring of Organizations: The Design of Craft-Based and Industrialized Construction Firms." Doctoral thesis, KTH, Sweden.

HööK, M., and Stehn, L. (2008). "Lean principles in industrialized housing production: the need for a cultural change." Lean Constr, J., Vol. 2, pp. 20-33.

Jensen, P., Lidelöw, H., and Olofsson T. (2015). "Product configuration in construction." Int. J. Mass Customisation, Vol. 5, No. 1, pp.73-92.

Khanzode, A., Fischer, M., and Reed, D. (2008). "Benefits and lessons learned of implementing building virtual design and construction (VDC) technologies for coordination of mechanical, electrical, and plumbing (MEP) system on a large healthcare project." Electron J. Inf. Technol. Constr., 13:324-42.

Korman, T. M. (2001). "Integrating Multiple Products over their Life Cycle: An Investigation of Mechanical, Electrical, and Plumbing Coordination." Ph.D. Thesis, Stanford University, Stanford, CA, June 2001.

Korman, T.M., Fischer, M.A., and Tatum, C.B. (2003). "Knowledge and Reasoning for MEP Coordination." ASCE, J. Constr. Eng. Manage., 129(6).

Korman, T.M., and Tatum, C.B. (2006). "Prototype Tool for Mechanical, Electrical, and Plumbing Coordination.” ASCE, J. Comp. in Civil Eng., 20(1).

Korman, T.M., and Lu, N. (2011). "Innovation and improvements of Mechanical Electrical and Plumbing Systems for Modular Construction using Building Information Modeling." Proceedings of the AEI 2011, ASCE, California, United States, pp. 448-455.

Kwok, T.H., Ye, H., Chen, Y., Zhou, C., and Xu, W. (2016). "Mass Customization: Reuse of Digital Slicing for Additive Manufacturing." Journal of Computing and Information Science in Engineering.

Li, X., Li, Z., and Wu, G. (2017). "Modular and Offsite Construction of Piping: Current Barriers and Route." Applied Sciences 7(6).

Lu, N. (2008). "Designers' and general contractors' perceptions of offsite construction techniques in the United State construction industry." International Journal of Construction Education and Research., V (4) 3, pp. 177-188.

Meyer, M., and Lehnerd, A. (1997). "The power of product platforms; Building value and cost leadership" The free press, New York.

Pine, B. J., (1993). "Mass Customization: The New Frontier in Business Competition." Harvard Business School Press, Boston, MA.

Riley, D.R., Varadan, P., James, J.S., and Thomas, H.R. (2005). "Benefit-cost metrics for design co- ordination of mechanical, electrical, and plumbing systems in multistory buildings." ASCE, J. Constr. Eng. Manage., 131(8):877-89.

Tseng, M.M., and Jiao, J. (1996). "Design for mass customization." CIRP annals Manufacturing Technology., Vol. 45, No. 1: 153-156

Wang, J., Wang, X., Shou, W., Chong, H., and Guo, J. (2016). "Building information modeling based integration of MEP layout designs and constructability." Autom. Constr,. 134-145. 